\title{
Digital Skills and Skills to Deal with COVID-19 Information: Sociodemographic Differences in a Cross-Sectional Study
}

\author{
Nina-Alexandra Götz ${ }^{\mathrm{a}, 1}$, Niels Hannemann ${ }^{\mathrm{a}}$, Lisa Schmidt ${ }^{\mathrm{a}}$ and Birgit Babitsch ${ }^{\mathrm{a}}$ \\ a Department New Public Health, Osnabrück University, Osnabrück, Germany
}

\begin{abstract}
In the current COVID-19 pandemic, the importance of digital media as a source of information for health-related behavior is impressively demonstrated. Until now there has been a lack of national research on the influence of socioeconomic differences in digital literacy and in the use of COVID-19 information. This study aims to analyze the influence of educational status and subjective social status on digital literacy and on the ability in using COVID-19 information. Data from a cross-sectional online survey were used. The results indicate social differences in digital literacy and in the ability to critically evaluate COVID-19 information.
\end{abstract}

Keywords. Digital skills, COVID-19 information, digital divide, educational status, subjective social status

\section{Introduction}

Digital health information has already been used as an effective tool in the fight against COVID-19. The question of equal opportunities with regard to digital competences has not yet been clarified. There are currently only few studies that deal with equity in health with regard to digital literacy specified as digital divide especially during a pandemic. This gives rise to the question of how digital skills and the skills to deal with reliable and correct COVID-19 information are distributed in the German population.

\section{Methods}

Data of a cross-sectional online survey were used. The study was conducted from April 29 to May 8 2020. 1.570 persons aged between 18- 74 years (MV = 46,08 years) participated with an equal gender distribution. The data were analyzed for differences of digital skills and the skills to deal with COVID-19 information by education status (ES) measured with the CASMIN classification [1] and subjective social status (SSS) [2]. Three SSS groups were created: low, medium and high SSS [3]. Digital literacy was measured using the newly developed, but not yet validated scale DIGCOM consisting of

\footnotetext{
${ }^{1}$ Corresponding Author, Dr. Nina-Alexandra Götz, Osnabrück University, Department of New Public Health, School of Human Sciences, Barbarastr. 22c, 49076 Germany; E-mail: nina.goetz@uni-osnabrueck.de
} 
11 response categories. The reliability is good (Cronbachs Alpha=0,887). Two closedended questions were used to ask whether people could assess that information about the COVID-19 pandemic was reliable and accurate. Pearson chi-square test was used to examine significant differences in ES and SSS.

\section{Results and Discussion}

Digital literacy differs significantly by SSS, but not by (ES) (see Table 1).

Table 1. Socio-economic differences in digital literacy

\begin{tabular}{|c|c|c|c|c|}
\hline & Low digital literacy & High digital literacy & Total & Sig. \\
\hline Low ES & $204(42.9 \%)$ & $272(57.1 \%)$ & $476(100.0 \%)$ & \multirow[b]{3}{*}{ n. s. } \\
\hline Middle ES & $315(38.8 \%)$ & $497(61.2 \%)$ & $812(100.0 \%)$ & \\
\hline High ES & $104(36.9 \%)$ & $178(63.1 \%)$ & $282(100.0 \%)$ & \\
\hline Low SSS & $163(44.1 \%)$ & $207(55.9 \%)$ & $370(100.0 \%)$ & \multirow[b]{3}{*}{0,001} \\
\hline Medium SSS & $276(42.4 \%)$ & $375(57.6 \%)$ & $651(100.0 \%)$ & \\
\hline High SSS & $184(33.5 \%)$ & $365(66.5 \%)$ & $549(100.0 \%)$ & \\
\hline Total & $623(39.7 \%)$ & $947(60.3 \%)$ & $1570(100.0 \%)$ & \\
\hline
\end{tabular}

More pronounced differences by ES and SSS are found in the distribution of the ability to evaluate information on the COVID-19 pandemic (see Table 2).

Table 2. Socio-economic differences regarding the ability to assess information of the COVID-19 pandemic as correct or reliable

\begin{tabular}{|c|c|c|c|c|}
\hline & Not certain & Certain & Total & Sig. \\
\hline Low ES & $211(44.3 \%)$ & $265(55.7 \%)$ & $476(100.0 \%)$ & \multirow[b]{3}{*}{0,018} \\
\hline Middle ES & $360(44.3 \%)$ & $452(55.7 \%)$ & $812(100.0 \%)$ & \\
\hline High ES & $99(35.1 \%)$ & $183(64.9 \%)$ & $282(100.0 \%)$ & \\
\hline Low SSS & $189(51.1 \%)$ & $181(48.9 \%)$ & $370(100.0 \%)$ & \multirow[b]{3}{*}{$\mathbf{0 , 0 0 0}$} \\
\hline Medium SSS & $283(43.5 \%)$ & $368(56.5 \%)$ & $651(100.0 \%)$ & \\
\hline High SSS & $198(36.1 \%)$ & $351(63.9 \%)$ & $549(100.0 \%)$ & \\
\hline Total & $670(42.7 \%)$ & $900(57.3 \%)$ & $1570(100.0 \%)$ & \\
\hline
\end{tabular}

The findings point to socioeconomic differences in digital literacy as well as in the critical handling of COVID-19 information and thus provide insights into the digital divide in society. Since the study was conducted as an online study, it can be assumed that, digital literacy is higher among the participants than in the population as a whole.

\section{Conclusion}

The data points to a digital divide in digital literacy and critical use of health information. As a result, this can be associated with negative consequences for health and healthcare.

\section{References}

[1] Lechert Y, Schroedter JH, Lüttinger P. Die Umsetzung der Bildungsklassifikation CASMIN für die Volkszählung 1970, die Mikrozensus-Zusatzerhebung 1971 und die Mikrozensen 1976-2004. Mannheim; 2006. [2] Adler NE, et al. Relationship of subjective and objective social status with psychological and physiological functioning: Preliminary data in healthy, White women. Health Psychology. 2000;19(6):586-592.

[3] Hoebel J, Kuntz B, Müters S, Lampert T. Subjektiver Sozialstatus und gesundheitsbezogene Lebensqualität bei Erwachsenen in Deutschland. ALLBUS 2010. Gesundheitswesen. 2013;75:643-51. 